\title{
Research Paper: Nicotine Dependence Severity and Revised Reinforcement Sensitivity Theory: Assessing the Mediating Role of Risky Decision Making Using Path Analysis
}

Kiomars Cheraghi $^{1}$ (D), Morad Rasouli-Azad ${ }^{2}$ (D), Hamid Reza Banafshe ${ }^{1,3}$ (D), Ali Yoonessi ${ }^{4}$ (D), Amir Ghaderi ${ }^{1,5}$ (D), Abdollah Omidi ${ }^{* *}$ (D)

1. Department of Addiction Studies, School of Medical, Kashan University of Medical Sciences, Kashan, Iran.

2. Department of Education and Psychology, College of Education, University of Raparin, Kurdistan Region, Iraq.

3. Department of Pharmacology, School of Medicine, Kashan University of Medical Sciences, Kashan, Iran.

4. Department of Neuroscience, School of Advanced Technologies in Medicine, Tehran University of Medical Sciences, Tehran, Iran.

5. Clinical Research Development Unit-Matini, Kargarnejad Hospital, Kashan University of Medical Sciences, Kashan, Iran.

6. Department of Clinical Psychology, School of Medicine, Kashan University of Medical Science, Kashan, Iran.

\begin{tabular}{|c|c|}
\hline $\begin{array}{l}\text { Use your device to san } \\
\text { and read the article online } \\
\end{array}$ & $\begin{array}{l}\text { Citation: Cheraghi K, Rasouli-Azad M, Banafshe HR, Yoonessi A, Ghaderi A, Omidi A. Nicotine Dependence Severity and Re- } \\
\text { vised Reinforcement Sensitivity Theory: Assessing the Mediating Role of Risky Decision Making Using Path Analysis. International } \\
\text { Journal of Medical Toxicology and Forensic Medicine. 2020; 10(4):30278. https://oi.org/10.32598/ijmtfm.v10i4.30278 } \\
\text { dol'https://doi.org/10.32598/ijmtfm.v10i4.30278 }\end{array}$ \\
\hline
\end{tabular}

\section{(1) (3)}

Article info:

Received: 04 May 2020

First Revision: 12 May 2020

Accepted: $01 \mathrm{Jul} 2020$

Published: 23 Nov 2020

\section{Keywords:}

Nicotine dependence severity, Risky decision making, Reinforcement sensitivity theory, BAS, BIS, FFFS

\section{A B STRACT}

Background: Gray's revised Reinforcement Sensitivity Theory(r-RST) is a neuropsychological explanation of personality that has been broadly used in substance use disorders. Although the Behavioral Approach System (BAS) is strongly related to nicotine dependence, findings in Behavioral Inhibition System (BIS) are controversial and there is little information about the role of the Fight/Flight/Freeze System (FFFS) in nicotine dependence. The purpose of the present study was to evaluate the mediating role of Risky Decision Making (RDM) in this relationship to clarify the controversy and fill the gap.

Methods: The final sample of this correlation study comprised of 347 university students (age, Mean \pm SD 23.2 \pm 6.7 ) who completed two self-report measures, including the Fagerstrom Test For Nicotine Dependence (FTND), Jackson-5 questionnaire of r-RST, and a computerized Iowa Gambling Task (IGT) to measure RDM. Pearson correlation and a path analysis framework were used to determine the simple, direct, and indirect effects of r-RST systems on nicotine dependence severity through RDM.

Results: Using Amos, path analyses demonstrated significant direct and indirect effects of BAS and FFFS/BIS on tobacco use. Also, the relationship between BAS/FFFS/BIS and tobacco use was shown to be mediated by RDM.

Conclusion: It was demonstrated that the relationship among BAS /FFFS/BIS and tobacco use can be partly explained using maladaptive RDM strategies, suggesting that decreasing reliance on decision-making in risky situations, while increasing the use of decision-making skills educations in risky situations, and increasing the use of alternative sensation and fun seeking by smoking and emotion regulation and mindfulness-based therapies might be effective interventions for subjects with heightened threat and reward sensitivity.

\footnotetext{
* Corresponding Author: Abdollah Omidi, PhD.

Address: Department of Addiction Studies, School of Medical, Kashan University of Medical Sciences, Kashan, Iran. Tel: +98 (31) 55463378

E-mail: abomidi20@yahoo.com
} 


\section{Introduction}

$\mathbf{R}$

einforcement Sensitivity Theory (RST) originally defined two motivational programs: a threat system (Behavioral Inhibition System (BIS)) and a reward system (Behavioral Approach System: (BAS)) [1]. Several studies have demonstrated the relationships between these systems and drinking, smoking, and gambling behavior [2, 3]. Research on original RST has generally indicated a positive relationship between substance use and BAS and problematic behaviors. In contrast, several studies on original RST have failed to find correlations between substance use behavior and BIS or they have shown that low BIS can anticipate substance use and problematic behaviors; such as drug and alcohol use, smoking, and gambling $[2,4]$.

Never smokers have low fun seeking and high BIS, experimenters have moderately high BIS and moderate reward responsiveness, and former smokers have high fun seeking, moderate BIS, high reward responsiveness, and high drive, whereas current smokers were low on all four of these characteristics [3]. There were important changes in the revision of RST, especially concerning the BIS. Also, the BAS as a function of the reward system is fairly fixed [4]. Based on r-RST, threat sensitivity is specified by the Fight-Flight-Freeze System (FFFS) $[5,6]$. The BIS functioning was previously considered as a threat detection system. But the BIS in r-RST begins its activation by a conflict that happens when both the FFFS and BAS are simultaneously activated [6].

Risky Decision Making (RDM) is a preference for rewards with aversive subsequences over safer alternatives and is an excessive risk-taking. Excessive risk-taking happens in some disorders and addiction. For example, in pathological gamblers, persons with Tourette syndrome, individuals with opiate and alcohol dependence, and cigarette smokers who seek drugs despite adverse consequences [7, 8]. Somatic Marker Theory (SMT) explains how emotion influences decision-making [9, 10]. SMT proposes that emotions are a factor in the interaction between human decision processes and environmental conditions, whereas other studies demonstrate that the personality influence on the performance was not entirely explained by emotional differences $[10,11]$. However, more studies are required to understand RDM. Although a non-addict individual usually prefers to decrease a risky reward as the risk of punishment increases, some individuals prefer the risky reward even when the risk of punishment increases as seen in some with substance abuse $[8,12,13]$.
Although independent roles of threat sensitivity, reward, and RDM in smoking have been widely evaluated, few studies have considered how these factors can predict nicotine dependence severity $[3,14]$. In addition, other factors (except RDM), including evaluative conditioning, affection, sadness and anxiety, risk level, framing issues, and psychological resilience mediate the correlation between reinforcement sensitivity and problematic behaviors $[15,16]$. It is hypothesized that a greater risk-taking behavior (e.g. smokers) is related to a greater BAS and less BIS, while a less risk-taking behavior (e.g. non-smokers) positively predicts less BAS and negatively predicts greater BIS. Individual differences in BAS and BIS are associated with substance misuse and gambling. BAS is linked to the high risk for being a drinker or smoker and positively is related to drinking, and drive and BAS are positively and negatively correlated with gambling, respectively $[2,17]$.

Other findings indicated that impaired performance or high scores on sensation seeking and the Gambling Task (GT) has not an important role in readiness to change smoking behavior, nicotine-dependence, and vice versa [18]. Although it has been proposed that BIS/BAS has a significant contribution to substance use, the different components of BAS sensitivity have a share to drinking and smoking than gambling. It has also proposed that sensitivity to punishment mediated the correlation between sensitivity to reward and non-gambling, and individual differences in sensitivity to punishment and sensitivity to reward are functionally related to gambling problems $[2,4,19]$.

The current study was done to evaluate the effects of RDM and BAS/FFFS/BIS sensitivity in the prediction of nicotine dependence severity in undergraduate students. It is hypothesized that FFFS can negatively predict greater risk-taking, which in turn positively predicts smoking. Thus, it is predicted that RDM can mediate the correlation between FFFS, BIS, and BAS and nicotine dependence severity; while BAS has also a direct correlation with nicotine dependence.

\section{Method}

\section{Participants}

A total of 347 undergraduate and postgraduate students were recruited from Tehran universities, Iran, from March 2018 to May 2019, of whom 91\% were males with an age range of 18-40 years diagnosed with nicotine dependence. The majority of participants were undergraduates $(80 \%)$ and single ( $84 \%$ ) (Table 1). The mean 
age of nicotine dependence was roughly three years, and the number of cigarettes smoked per week was 45.7. A certified clinical psychologist $(\mathrm{K} \mathrm{CH})$ made a diagnosis of nicotine dependence through a formal clinical interview (DSM-IV) [20]. Exclusion criteria included past or current psychotic, mania, and major depressive episodes, as well as substance dependence or abuse. The study was accepted by the Kashan University of Medical Sciences ethical committee (Ethical Code: KAUMS. ETHIC.96021).

Participants were informed about the study objectives and their informed written consent was obtained. Besides, an evaluation battery, which included the following measures was completed.

\section{Measures}

Structured Clinical Interview for DSM-IV Axis I Disorders (SCID-I):

SCID-I has a screening form evaluating symptomology for various axis I disorders [20]. Diagnostic agreements between retest and test SCID administration were fair to good for most diagnostic categories in the Iranian population [21].

\section{Jackson-5 scale}

Jackson developed this 30-item scale to measure rRST [22]. It consists of five sub-systems: Behavioral Inhibition System (BIS), Behavioral Activation System (BAS), flight, fight, and freeze system - each subscale contains 6 items. In an Iranian sample, the Cronbach's alpha of the scale was shown to be as follows: $\mathrm{r}-\mathrm{BAS}=0.81 ; \mathrm{r}-\mathrm{BIS}=0.88$, fight $=0.74$, flight $=0.72$, and freeze $=0.77$ [23]. The scale showed good and acceptable reliability in the present study (Cronbach's $\alpha=0.68$ to 0.87 ) (Table 2).

\section{Iowa Gambling Task (IGT)}

IGT [24] simulates real-life decision-making by testing the ability of individuals to sacrifice immediate rewards $[25,26]$. We used a computerized version of the IGT from the Psychology Experimental Building Language (PEBL) test battery. Briefly, participants had to choose one card from four possible decks (A-D). The individuals had to make 100 choices, losing and winning a certain amount of money in each choice. After each choice, the individuals received feedback on the computer screen, telling them how much money they had lost and won. The final IGT score was then obtained with subtracting the total number of advantageous decks from that of the disadvantageous decks $[(\mathrm{A}+\mathrm{B})-(\mathrm{C}+\mathrm{D})]$ for 100 choices. Higher scores demonstrated more RDM among individuals.

\section{The Fagerstrom Test for Nicotine Dependence (FTND)}

FTND is a standard tool for determining the severity of physical nicotine dependence [27]. It was developed to provide an ordinal indicator of cigarette-related nicotine addiction. The yes / no items are graded from 0 to 1 and multiple-choice items are scored from 0 to 3 . The scores are summed up to give an overall score of 0-10. The higher the Fagerström total score, the more severe the physical dependence on nicotine of the patient is. In the current study, the questionnaire showed good reliability (Cronbach's $=\alpha$ 0.88) (Table 2).

\section{Data analysis}

Pearson's correlation coefficient was used to test the correlation between variables (Table 2). Also, we used a path analysis using AMOS to examine the roles of RDM (IGT scores) in the associations between three brain behavioral systems (r-RST) and the nicotine dependence severity (FTND scores). Path analyses were performed using AMOS version 21.0 to determine the best fit model for predicting nicotine dependence. A pseudo latent variable regression was employed with one indicator for each latent construct corrected for measurement error. The variance of the error linked to each indicator was defined as the sum of its variance, and one minus its approximate alpha coefficient to correct random error measurement [28]. The model fit was evaluated using generally accepted Chi-square thresholds (Chi-square/ $\mathrm{df}=1-3)$, the root mean square error of approximation (RMSEA 0.06-0.08), the comparative fit index (CFI $>0.95)$, the goodness-of-fit (GFI $>0.90)$, the adjusted goodness-of-fit (AGFI $>0.85$ ), and Tucker-Lewis index (TLI $>0.85)$.

\section{Results}

Participants' demographic information and other clinical variables are presented in Table 1. Also, the means, standard deviation, Pearson's correlation coefficients, and Cronbach's alpha for each scale are reported in Table 2. Pearson's correlation coefficient was used to test the correlation between variables. Accordingly, a significant positive and negative associations between 
Table 1. Demographic and clinical characteristics of students with nicotine-dependence

\begin{tabular}{|c|c|}
\hline Variables & 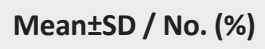 \\
\hline Age (y) & $23.2 \pm 6.7$ \\
\hline \multirow{2}{*}{\multicolumn{2}{|c|}{$314(91 \%)$}} \\
\hline & \\
\hline Female & $33(9.0 \%)$ \\
\hline \multirow{2}{*}{\multicolumn{2}{|c|}{ Undergraduate students }} \\
\hline & \\
\hline Postgraduate & $71(20 \%)$ \\
\hline Single & $294(84 \%)$ \\
\hline Marital status & $51(14.7 \%)$ \\
\hline Other & $2(1.3 \%)$ \\
\hline Age of onset of cigarette smoking & $20.1 \pm 2$ \\
\hline Duration of nicotine dependence (years) & $3 \pm 1.9$ \\
\hline Number of cigarettes per week & $45.7 \pm 31.5$ \\
\hline History of cession (above one month) & $73(21 \%)$ \\
\hline
\end{tabular}

Table 2. Correlation matrix, Mean $\pm S D$, and reliability coefficients for variables $(n=347)$

\begin{tabular}{|c|c|c|c|c|c|}
\hline Variables & 1 & 2 & 3 & 4 & 5 \\
\hline \multicolumn{6}{|l|}{$r-R S T$} \\
\hline 1: r-BAS & 1 & $-0.26 * *$ & $-0.15^{* *}$ & $0.59 * *$ & $0.51^{* *}$ \\
\hline 2: r-BIS & & 1 & 0.06 & $-0.33^{* *}$ & $-0.22 * *$ \\
\hline 3: r-FFFS & & & 1 & $-0.19 * *$ & -0.05 \\
\hline 4: IGT & & & & 1 & $0.63 * *$ \\
\hline 5: FTND & & & & & 1 \\
\hline$\alpha$ & 0.76 & 0.87 & 0.80 & 0.90 & 0.88 \\
\hline M & 17.6 & 18.4 & 54.6 & 8.8 & 5.1 \\
\hline SD & 3.7 & 4.2 & 3.9 & 19.7 & 2.3 \\
\hline Min & 12 & 11 & 42 & -32 & 1 \\
\hline Max & 26 & 25 & 64 & 39 & 9 \\
\hline
\end{tabular}

r-BAS: Revised Behavioral Approach System; r-BIS: Revised Behavioral Inhibition System; r-FFFS: Revised Fight/Flight/ Freeze Systems; IGT: Iowa Gambling Task; FTND: Fagerstrom Test for Nicotine Dependence; a: Cronbach's alpha; Min: Minimum; Max: Maximum.

Sig: $\mathrm{P}<0.05$.

$* * \mathrm{P}<0.01$. 
Table 3. The models' goodness of fit statistics

\begin{tabular}{ccccccccccc}
\hline Model & $\boldsymbol{\chi}^{\mathbf{2}}$ & $\mathbf{d f}$ & $\boldsymbol{\chi}^{2} / \mathbf{d f}$ & AIC & BIC & RMSEA & CFI & GFI & AGFI & TLI \\
\hline 1 & 5.6 & 1 & 5.6 & 33.6 & 87.5 & 0.11 & 0.98 & 0.99 & 0.90 & 0.88 \\
2 & 3.8 & 2 & 1.9 & 29.8 & 79.8 & 0.05 & 0.99 & 0.99 & 0.96 & 0.97 \\
\hline
\end{tabular}

$X^{2}$ : Chi-square; df: Degrees of Freedom; AIC: Akaike Information Criterion; RMSEA: Root Mean Square Error of Approximation; BIC: Bayesian Information Criterion; CFI: Comparative Fit Index; GFI: Goodness of Fit Index; AGFI: Adjusted Goodness of Fit Index; TLI: Tucker-Lewis Index

BAS and BIS and RDM and the frequency of nicotine dependence, respectively $(\mathrm{P}<0.01)$ (Table 2$)$.

The indirect and direct effects of the mediation models were tested by the mediation analyses (Figures 1 and 2). Figure 1 demonstrates the roles of RDM (IGT scores) in the relationships between r-RST constructs (BAS, BIS, and FFFS), and the nicotine dependence severity in cigarette smokers. RDM as measured by IGT scores was associated with nicotine dependence severity. The first model indicated all direct and indirect effects among three constructs of r-RST and nicotine dependence. The fit indices for the first model demonstrated an acceptable fit with a high RMSEA. The fit indices for the model were as follows: $\mathrm{CFI}=0.98, \mathrm{GFI}=0.99, \mathrm{AGFI}=0.90, \mathrm{RM}$ $\mathrm{SEA}=0.11$, and $90 \% \mathrm{CI}=0.04-0.21$. The findings showed that BIS and FFFS had no direct relationship with nicotine dependency. BAS $(\beta=0.53, \mathrm{P}<0.001)$, BIS $(\beta=-0.19$, $\mathrm{P}<0.001)$ and FFFS $(\beta=-0.10, \mathrm{P}<0.05)$ significantly predicted IGT scores. Also, IGT scores directly predicted nicotine dependency $(\beta=0.52, \mathrm{P}<0.001)$.

The results of Preacher and Hayes' macro PROCESS using bootstrapping with 5000 resamples showed that

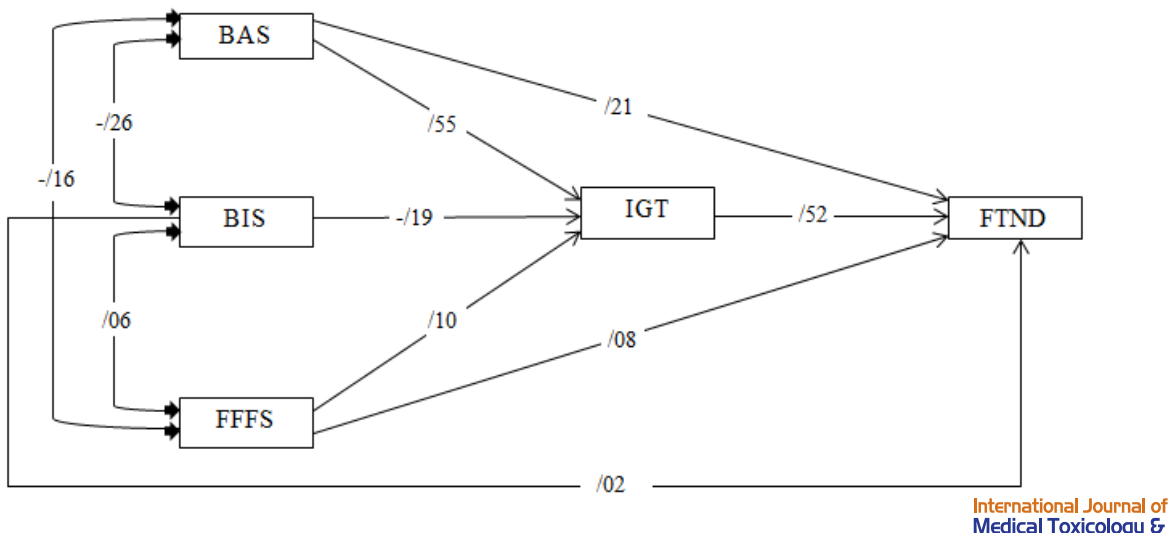

International Journal of Figure 1. The first model illustrates direct and indirect standardized effects between revised behavioral approach system (rRST) subscales and nicotine dependency via the mediating role of risky decision making

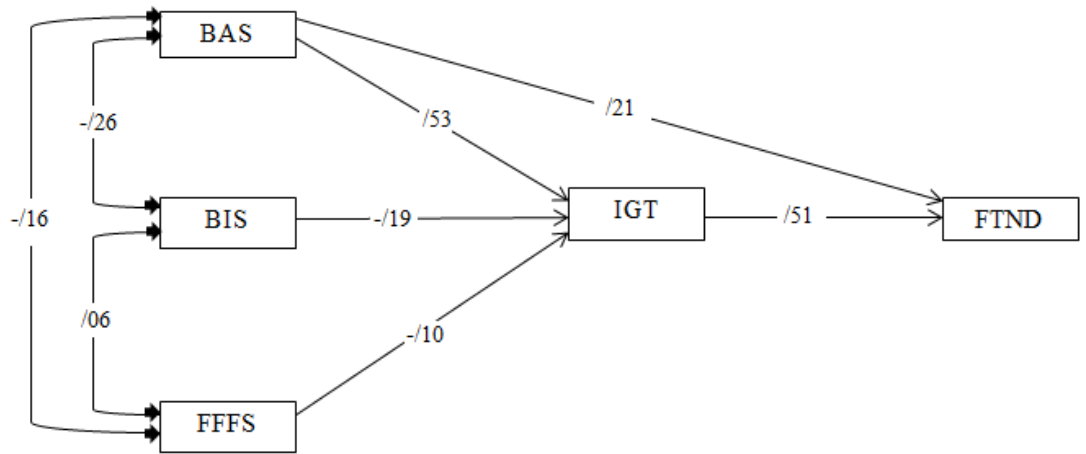
International Journal of
Medical Toxicology \& Forensic Medicine Figure 2. The second model illustrates only indirect standardized effects between behavioral inhibition system (BIS) and fight/ flight/freeze systems (FFFS) and nicotine dependence severity 
BIS $(\beta=0.002$, bootstrap $\mathrm{SE}=0.048$, and $95 \% \mathrm{CI}=0.05$ $0.046)$ and FFFS $(\beta=0.048$, bootstrap $\mathrm{SE}=0.047$, and $95 \% \mathrm{CI}=0.001-0.098)$ had no direct relationship with the nicotine dependence severity. BAS had direct $(\beta=0.13$, bootstrap $\mathrm{SE}=0.07$, and $95 \% \mathrm{CI}=0.06-0.20)$, and indirect relationship with nicotine dependency $(\beta=0.16$, bootstrap $\mathrm{SE}=0.04$, and $95 \% \mathrm{CI}=0.12-0.30)$ through $\mathrm{RDM}$.

The second model was drawn by the omission of the direct path from BIS and FFFS to nicotine dependency. These findings suggested that BIS and FFFS were not directly associated with the nicotine dependence severity, but they were indirectly related. The fit indices for the second model showed a more acceptable fit and less RMSEA in comparison with the first one $(\mathrm{CFI}=0.99$, GFI $=0.99, \quad$ AGFI $=0.96, \quad$ RMSEA $=0.05, \quad$ and $90 \%$ $\mathrm{CI}=0.01-0.12$ ) (Table 3). The second model, however, significantly showed improved fit, demonstrating that the second model offers a better explanation of the data (Table 3). Generally, $43 \%$ of the variance in nicotine dependence severity was explained.

\section{Discussion}

In the current research, we a conceptual model in RDM mediated the correlation between FFFS and BIS sensitivity and nicotine dependence severity. Also, FFFS and BIS were shown to have a significant indirect association with nicotine dependence severity via RDM. BAS had significant positive direct and indirect relationships with nicotine dependence severity. As expected, nicotine dependence severity was positively correlated with the individual with high risk-taking in IGT and negatively associated with the individual with low risk-taking in IGT. However, the individual with high risk-taking in IGT was significantly associated with tobacco use.

These findings are consistent with studies, which reported the individual with high risk-taking behaviors to be a risk factor for problematic behaviors, such as smoking and drinking, and the individual with low risk-taking behaviors to be a protective factor against problematic behaviors. In general, the interaction between emotions, human decision-making processes, environmental conditions, and personality-related differential emotional responsiveness can modulate somatic marker development $[10,11]$. However, it has been suggested that the crucial mechanisms and meta-decision variables may be shared across domains. Also, disinhibition is more strongly associated with the wanting component of reward-based decision making, whereas substance abuse behavior is associated more with the learning of long-term actionreward contingencies [29, 30].
Stimulant users take risks more frequently but they are not less sensitive to punishments, and also the individuals with the higher time preference rate or the lower coefficient in the risk aversion become drinkers or gamblers on the horses and pachinko. Moreover, risk preference in the Risky Decision-Making Task (RDT) forecasts other traits related to nicotine and substance use disorder $[14,31,32]$. Overall, based on our results, RDM was positively associated with nicotine dependence severity, which is consistent with some previous studies [32] However, it is inconsistent with the majority of studies that reported RDM to be negatively associated with alcohol drinking problems and impulsivity and decisionmaking are the strongest forecasters of alcohol use.

Fearless children in RDM and those with drivers at high crash risk either adopt a high-risk approach or a very cautiously approach [33]. Recent studies have shown different factors affecting RDM [29, 30]. RDM is measured via distinct forms of different tests and tasks [14, 33, 34]. Further studies examining different factors affecting $\mathrm{RDM}$ and designing instruments to measure RDM are needed to clarify the role of RDM in smoking. Consistent with past evidence, BAS was demonstrated to have a significant positive relationship with tobacco use, and drug and alcohol use was positively related to BAS $[2,4,34]$.

It has proposed that both BAS and negative affect are independently linked to risky performance on IGT, and BAS is related to high risk for being a drinker or smoker, and it is positively associated with drinking, driving, and drug addiction $[2,4]$. In our study, FFFS showed no direct negative relationship with tobacco use. Although we did not find researches study on the relationships between FFFS and smoking, there are many studies on the relationship between FFFS and other problematic behaviors, The results indicated that primary psychopath is negatively associated with the BIS as well as the FFFS. FFFS also mediates reactions to conditioned and unconditioned aversive stimuli. The fear and higher FFFS sensitivity result in less driving enforcement under stress and the stress and FFFS also are positively related to average bet-size. Neuroticism is associated with revised FFFS-fear, BIS-anxiety, and extraversion to FFFS-fear and BAS. Also, FFFS is more closely associated with aversive than avoidant indecision and BIS only anticipated aversive indecision [15, 35-38].

In our study, BIS showed no direct negative correlation with tobacco use. Although drug and alcohol use is negatively associated with BIS, and BIS contributes to substance use, reward responsiveness (rather than BIS) protects against engagement in the risky health behav- 
iors, (e.g. sex, drug, alcohol, tobacco use, inactivity, and poor diet) $[4,39,40]$. The results of studies have indicated four profiles as follows: 1 . Never smokers have the low fun seeking and high BIS; 2. Experimenters have the moderately high BIS, moderate reward responsiveness, and high fun seeking; 3. Former smokers have moderate BIS, high reward responsiveness, high fun seeking, and high drive; 4. Current smokers were low on all four of these characteristics [3].

In general, there are inconsistencies in the previous studies and further studies are needed. However, the current finding may be consistent or inconsistent with the RDM relationship with cigarette use. Findings support that cocaine and marijuana use forecast IGT performance, and impulsivity and risk-taking propensity are related to smoking [41, 42]. Although acute drugs (nicotine, amphetamine, diazepam, morphine, and ethanol) abuse can modulate risk-taking, either growing or deducting preference for highly rewarding but risky options, the mediators, such as executive dysfunction in alcohol dependence delays transition from ambiguous to risky situations during IGT [43, 44]. RDM theories of drug use argue that the consumption of the drug is related to decision-making in risky situations. Thus, consistent with RDM theories of drug use, those who are highly sensitive to threats are less smoker, too. Also, it should be noted that the indirect correlation between smoking and FFFS was very weak and the inclusion of the indirect path to the model did not significantly improve model fit.

This proposes that there is no direct correlation between cigarette use and FFFS, and there is an indirect association between RDM and FFFS. Therefore, our findings suggest that no link between sensitivity to threat and tobacco use can be explained by considering how subjects make decisions in the risky situations. Obviously, heightened sensitivity to threats can lead to the use of a lower rate of decision-making in risky situations, which may then result in less tobacco use. Although no past evidence has shown RDM to mediate the correlation between tobacco use and reinforcement sensitivity, several studies have separately considered the relationship between RDM, reinforcement sensitivity, tobacco and substance use, and risky behaviors. Studies that have separately considered the relationship between RDM and RST and smoking are inconsistent with our findings. There is no significant mediation between BAS and substance use, and impaired GT performance and high sensation seeking have not an important role in readiness to change smoking behavior and nicotine dependence $[18,45]$.
Consequently, our study is unique because it revealed that RDM mediates the correlation between tobacco use and reinforcement sensitivity. However, it should be stated that the lack of BAS to predict substance use in the Stenason and Vernon (2016) study and no significant relationship between impaired GT performance and smoking in the Harmsen (2005) study were unusual [18, 45]. These unusual findings are inconsistent with the current study and suggest a need to evaluate both state mood and Zpersonality BAS when trying to explain poor IGT performance, particularly in clinical populations [34]. Previous studies have generally revealed that BAS (fun seeking) is related to high risk for being a smoker [2], suggesting that reinforcement sensitivity might more relevant as the condition to tobacco use increases. This is consistent with some investigations. The research predicted a relationship between BAS and substance abuse, and high BAS was positively associated with increased desire for alcohol drinking, and BIS/BAS had a significant contribution to substance use $[4,46,47]$.

Our results provided treatment implications and revealed specific reinforcement sensitivity pathways to tobacco use, where BAS sensitivity and FFFS sensitivity were indirectly linked to tobacco use through decisionmaking skills education in risky situations. Also, BAS sensitivity was directly and indirectly linked to tobacco use through alternative sensation and fun seeking, such as combination of exercise and smoking, emotion regulation, and mindfulness-based therapies. Specifically, our study demonstrated that greater use of decision-making in risky situations in people highly sensitive to reward is linked to high smoking whereas when subjects are highly sensitive to threat, their behavior is associated with less decisionmaking in risky situations and they tend to smoke.

Our results indicated that treatment programs may be useful for those at high risk for smoking behavior. Increasing reliance by training decision-making skills in risky situations and increasing the use of alternative sensation and fun seeking to smoking, as well as emotion regulation and mindfulness-based therapies are effective in tobacco use interventions for subjects who are highly sensitive to reward. However, increasing reliance by training decisionmaking skills in risky situations is valuable for subjects who are highly sensitive to threat. Consistent with our results, examining the effectiveness of decision-making, cognitive behavioral therapies, and mindfulness skills interventions can be useful to address specific personality traits that increase the risk of smoking [48-51]. 


\section{Limitation}

However, it should be considered that our study had many limitations. It was based on self-report measures. Subjects were needed to mention their decision-making responses in risky situations in IGT and to average their responses in all risky situations experienced. However, it has been demonstrated that the type and severity of a risky situation can influence decision-making. This study was done to the effects of RDM using our used tools. Interpretation of the findings regarding FFFS should also be made cautiously, as it is a recently-developed scale that has not yet been widely validated. Another weakness of the current study was that participants were selected using convenient sampling and they used the computer; therefore, it cannot be assured that the samples were free of selection bias. Thus, our findings cannot be generalized to other populations, such as those who are not familiar with or do not use the computer.

\section{Conclusion}

Overall, our findings suggest that the tobacco use of people highly sensitive to threats might be an outcome of ineffectual use of decision-making strategies to deal with a risky situation, specifically highlighting the importance of RDM in the prediction of tobacco use. Further examination of community and various samples, clinical and non-clinical, is recommended to enhance understanding of the role that RDM and reinforcement sensitivity play in tobacco use problems.

\section{Ethical Considerations}

\section{Compliance with ethical guidelines}

All ethical principles were considered in this article. The participants were informed about the purpose of the research and its implementation stages; they were also assured of the confidentiality of their information. Moreover, they were allowed to leave the study whenever they wish, and if desired, the results of the research would be available to them.

\section{Funding}

This research was supported by the Clinical Research Development Unit-Matini/Kargarnejad Hospital, Kashan University of Medical Sciences (KAUMS/96021).

\section{Author's contributions}

All authors contributed equally in preparing all parts of the research.

\section{Conflict of interest}

The authors declared no conflict of interest.

\section{References}

[1] Gray, J. A. Framework for a taxonomy of psychiatric disorder. In van Goozen SH M, Van de Poll NE, Sergeant JA. editors. Emotions: Essays on emotion theory. New Jersey: Lawrence Erlbaum Associates, Inc.; 1994. https://psycnet. apa.org/record/1994-97189-002

[2] O'Connor RM, Stewart SH, Watt MC. Distinguishing BAS risk for university students' drinking, smoking, and gambling behaviors. Personality and Individual Differences. 2009; 46(4):514-9. [DOI:10.1016/j.paid.2008.12.002]

[3] Baumann MR, Oviatt D, Garza RT, Gonzalez-Blanks AG, Lopez SG, Alexander-Delpech P, et al. Variation in BAS-BIS profiles across categories of cigarette use. Addictive Behaviors. 2014; 39(10):1477-83. [DOI:10.1016/j.addbeh.2014.05.028] [PMID] [PMCID]

[4] Franken IH, Muris P. BIS/BAS personality characteristics and college students' substance use. Personality and Individual Differences. 2006; 40(7):1497-503. [DOI:10.1016/j. paid.2005.12.005]

[5] Gray JA, McNaughton N. The neuropsychology of anxiety: Reprise. In Nebraska symposium on motivation. 1996; 43:61-134. University of Nebraska Press. https:// books.google.com/books?hl=en\&lr=\&id=4EggiquttMC\&oi=fnd\&pg=PA61\&dq=

[6] Deary V, Johnson W. Looking for the fundamentals of human nature. Journal of Mental Health. 2009; 18(6):459-66. [DOI:10.3109/09638230902946767]

[7] Brand M, Roth-Bauer M, Driessen M, Markowitsch HJ. Executive functions and risky decision-making in patients with opiate dependence. Drug and Alcohol Dependence. 2008; 97(1-2):64-72. [DOI:10.1016/j.drugalcdep.2008.03.017] [PMID]

[8] Brevers D, Bechara A, Cleeremans A, Kornreich C, Verbanck P, Noël X. Impaired decision-making under risk in individuals with alcohol dependence. Alcoholism: Clinical And Experimental Research. 2014; 38(7):1924-31.[DOI:10.1111/ acer.12447] [PMID] [PMCID]

[9] Dunn BD, Dalgleish T, Lawrence AD. The somatic marker hypothesis: A critical evaluation. Neuroscience \& Biobehavioral Reviews. 2006; 30(2):239-71. [DOI:10.1016/j.neubiorev.2005.07.001] [PMID]

[10] Bechara A, Damasio AR. The somatic marker hypothesis: A neural theory of economic decision. Games and Economic Behavior. 2005; 52(2):336-72. [DOI:10.1016/j.geb.2004.06.010] 
[11] Mardaga S, Hansenne M. Personality and skin conductance responses to reward and punishment. Journal of Individual Differences. 2011.[DOI:10.1027/1614-0001/a000057]

[12] Simon NW, Gilbert RJ, Mayse JD, Bizon JL, Setlow B. Balancing risk and reward: A rat model of risky decision making. Neuropsychopharmacology. 2009; 34(10):2208-17. [DOI:10.1038/ npp.2009.48] [PMID] [PMCID]

[13] Verdejo-Garcia A, Chong TT, Stout JC, Yücel M, London ED. Stages of dysfunctional decision-making in addiction. Pharmacology Biochemistry and Behavior. 2018; 164:99-105. [DOI:10.1016/j.pbb.2017.02.003] [PMID]

[14] Gabriel DB, Freels TG, Setlow B, Simon NW. Risky decision-making is associated with impulsive action and sensitivity to first-time nicotine exposure. Behavioural Brain Research. 2019; 359:579-88. [DOI:10.1016/j.bbr.2018.10.008] [PMID]

[15] Brunborg GS, Johnsen BH, Mentzoni RA, Molde H, Pallesen S. Individual differences in evaluative conditioning and reinforcement sensitivity affect bet-sizes during gambling. Personality and Individual Differences. 2011; 50(5):729-34. [DOI:10.1016/j.paid.2010.12.026]

[16] Xing C, Sun JM. The role of psychological resilience and positive affect in risky decision-making. International Journal of Psychology. 2013; 48(5):935-43. [DOI:10.1080/00207594.201 2.729840] [PMID]

[17] Kim DY, Lee JH. Effects of the BAS and BIS on decisionmaking in a gambling task. Personality and Individual Differences. 2011; 50(7):1131-5. [DOI:10.1016/j.paid.2011.01.041]

[18] Harmsen H, Bischof G, Brooks A, Hohagen F, Rumpf HJ. The relationship between impaired decision-making, sensation seeking and readiness to change in cigarette smokers. Addictive Behaviors. 2006; 31(4):581-92. [DOI:10.1016/j.adde beh.2005.05.038] [PMID]

[19] Gaher RM, Hahn AM, Shishido H, Simons JS, Gaster S. Associations between sensitivity to punishment, sensitivity to reward, and gambling. Addictive Behaviors. 2015; 42:180-4. [DOI:10.1016/j.addbeh.2014.11.014] [PMID]

[20] First MB, Spitzer RL, Gibbon M, Williams JB. The structured clinical interview for DSM-III-R Personality Disorders (SCID-II). Part I: Description. Journal of Personality disorders. 1995; 9(2):83-91. [DOI:10.1521/pedi.1995.9.2.92]

[21] Sharifi V, Assadi SM, Mohammadi MR, Amini H, Kaviani $\mathrm{H}$, Semnani $\mathrm{Y}$, et al. A persian translation of the structured clinical interview for diagnostic and statistical manual of mental disorders: Psychometric properties. Comprehensive Psychiatry. 2009; 50(1):86-91. [DOI:10.1016/j.comppsych.2008.04.004] [PMID]

[22] Jackson CJ. Jackson-5 scales of revised Reinforcement Sensitivity Theory (r-RST) and their application to dysfunctional real world outcomes. Journal of Research in Personality. 2009; 43(4):556-69. [DOI:10.1016/j.jrp.2009.02.007]

[23] Hasani J, Rasoli Azad M. [Psychometric properties of Jackson's five factor questionnaire: Scales of revised Reinforcement Sensitivity Theory (r-RST) (Persian)]. Journal of Research in Psychological Health. 2012; 6(3):60-73. http://rph. khu.ac.ir/article-1-1528-fa.html

[24] Newton-Howes G, Clark LA, Chanen A. Personality disorder across the life course. The Lancet. 2015; 385(9969):727-34. [DOI:10.1016/S0140-6736(14)61283-6] [PMID]
[25] Damasio AR. The somatic marker hypothesis and the possible functions of the prefrontal cortex. Philosophical Transactions of the Royal Society of London. Series B: Biological Sciences. 1996; 351(1346):1413-20. [DOI:10.1098/rstb.1996.0125] [PMID]

[26] Damasio AR. William James and the modern neurobiology of emotion. Emotion, evolution and rationality. 2004. [DOI:10.1093/acprof:oso/9780198528975.003.0001]

[27] Heatherton TF, Kozlowski LT, Frecker RC, Fagerstrom KO. The Fagerström test for nicotine dependence: A revision of the Fagerstrom Tolerance Questionnaire. British Journal of Addiction. 1991; 86(9):1119-27.[DOI:10.1111/j.1360-0443.1991. tb01879.x] [PMID]

[28] Bollen KA. The consequences of measurement error. Structural Equations With Latent Variables. 1989; 151-78. [DOI:10.1002/9781118619179.ch5]

[29] Byrne KA, Patrick CJ, Worthy DA. Striatal dopamine, externalizing proneness, and substance abuse: Effects on wanting and learning during reward-based decision making. Clinical Psychological Science. 2016; 4(5):760-74. [DOI:10.1177/2167702615618163] [PMID] [PMCID]

[30] Boureau YL, Sokol-Hessner P, Daw ND. Deciding how to decide: Self-control and meta-decision making. Trends in Cognitive Sciences. 2015; 19(11):700-10. [DOI:10.1016/j. tics.2015.08.013] [PMID]

[31] Leland DS, Paulus MP. Increased risk-taking decisionmaking but not altered response to punishment in stimulantusing young adults. Drug and Alcohol Dependence. 2005; 78(1):83-90. [DOI:10.1016/j.drugalcdep.2004.10.001] [PMID]

[32] Ida T, Goto R. Interdependency among addictive behaviours and time/risk preferences: Discrete choice model analysis of smoking, drinking, and gambling. Journal of Economic Psychology. 2009; 30(4):608-21. [DOI:10.1016/j. joep.2009.05.003]

[33] Nystrom B, Bengtsson H. Temperamental influences on children's risk-taking in decision making: A dual process, multi-level analysis. Personality and Individual Differences. 2016; 89:177-81. [DOI:10.1016/j.paid.2015.10.020]

[34] Suhr JA, Tsanadis J. Affect and personality correlates of the Iowa Gambling Task. Personality and Individual Differences. 2007; 43(1):27-36. [DOI:10.1016/j.paid.2006.11.004]

[35] Morton RD, White MJ. Revised reinforcement sensitivity theory: The impact of FFFS and stress on driving. Personality and Individual Differences. 2013; 54(1):57-63.[DOI:10.1016/j. paid.2012.08.005]

[36] Heym N, Ferguson E, Lawrence C. An evaluation of the relationship between Gray's revised RST and Eysenck's PEN Distinguishing BIS and FFFS in Carver and White's BIS/BAS scales. Personality and Individual Differences. 2008; 45(8):70915. [DOI:10.1016/j.paid.2008.07.013]

[37] Hardie SM, Wright L. The relationship between Revised Reinforcement Sensitivity Theory (rRST), handedness and indecision. Personality and Individual Differences. 2013; 55(3):312-6. [DOI:10.1016/j.paid.2013.03.004]

[38] Pickering AD, Corr PJ. JA Gray's reinforcement sensitivity theory (RST) of personality. The SAGE handbook of personality: Theory and Assessment Personality Measurement And Testing. 2008; 2:239-55.[DOI:10.4135/9781849200462.n11] 
[39] Wytykowska A, Lewicka M. Learning the affective value of target categories: The role of category valence and the Behavioural Inhibition System (BIS). Personality and Individual Differences. 2011; 50(7):944-8. [DOI:10.1016/j.paid.2010.09.003]

[40] Voigt DC, Dillard JP, Braddock KH, Anderson JW, Sopory $\mathrm{P}$, Stephenson MT. BIS/BAS scales and their relationship to risky health behaviours. Personality and Individual Differences. 2009; 47(2):89-93. [DOI:10.1016/j.paid.2009.02.003]

[41] Ryan KK, MacKillop J, Carpenter MJ. The relationship between impulsivity, risk-taking propensity and nicotine dependence among older adolescent smokers. Addictive Behaviors. 2013; 38(1):1431-4.. [DOI:10.1016/j.addbeh.2012.08.013] [PMID] [PMCID]

[42] Verdejo-Garcia A, Benbrook A, Funderburk F, David P, Cadet JL, Bolla KI. The differential relationship between cocaine use and marijuana use on decision-making performance over repeat testing with the Iowa Gambling Task. Drug and Alcohol Dependence. 2007; 90(1):2-11.[DOI:10.1016/j.drugalcdep.2007.02.004] [PMID] [PMCID]

[43] Kim YT, Sohn H, Jeong J. Delayed transition from ambiguous to risky decision making in alcohol dependence during Iowa Gambling Task. Psychiatry Research. 2011; 190(2-3):297303. [DOI:10.1016/j.psychres.2011.05.003] [PMID]

[44] Mitchell MR, Vokes CM, Blankenship AL, Simon NW, Setlow B. Effects of acute administration of nicotine, amphetamine, diazepam, morphine, and ethanol on risky decisionmaking in rats. Psychopharmacology. 2011; 218(4):703-12. [DOI:10.1007/s00213-011-2363-8] [PMID] [PMCID]

[45] Stenason L, Vernon PA. The Dark Triad, reinforcement sensitivity and substance use. Personality and Individual Differences. 2016; 94:59-63. [DOI:10.1016/j.paid.2016.01.010]

[46] Franken IH, Muris P, Georgieva I. Gray's model of personality and addiction. Addictive Behaviors. 2006; 31(3):399-403. [DOI:10.1016/j.addbeh.2005.05.022] [PMID]

[47] Franken IH. Behavioral Approach System (BAS) sensitivity predicts alcohol craving. Personality and Individual Differences. 2002; 32(2):349-55. [DOI:10.1016/S0191-8869(01)00030-7]

[48] Dawkins L, Powell JH, Pickering A, Powell J, West R. Patterns of change in withdrawal symptoms, desire to smoke, reward motivation and response inhibition across 3 months of smoking abstinence. Addiction. 2009; 104(5):850-8 [DOI:10.1111/j.1360-0443.2009.02522.x] [PMID] [PMCID]

[49] Cassotti M, Moutier S. How to explain receptivity to conjunction-fallacy inhibition training: Evidence from the Iowa Gambling Task. Brain and Cognition. 2010; 72(3):378-84. [DOI:10.1016/j.bandc.2009.11.004] [PMID]

[50] Ivory NJ, Kambouropoulos N. Coping mediates the relationship between revised reinforcement sensitivity and alcohol use. Personality and Individual Differences. 2012 52(7):822-7. [DOI:10.1016/j.paid.2012.01.013]

[51] Vidrine JI, Businelle MS, Cinciripini P, Li Y, Marcus MT, Waters AJ, et al. Associations of mindfulness with nicotine dependence, withdrawal, and agency. Substance abuse. 2009; 30(4):318-27. [DOI:10.1080/08897070903252973] [PMID] [PMCID] 